\title{
Axillary Lymph Node Level III
}

National Cancer Institute

\section{Source}

National Cancer Institute. Axillary Lymph Node Level III. NCI Thesaurus. Code C123463.

Axillary lymph nodes located superomedial to pectoralis minor. 